\title{
Analyses of Habituation in Caenorhabditis elegans
}

\author{
Jacqueline K. Rose and Catharine H. Rankin \\ Department of Psychology, University of British Columbia, Vancouver BC V6T 1Z4, Canada
}

\begin{abstract}
Although the nonassociative form of learning, habituation, is often described as the simplest form of learning, remarkably little is known about the cellular processes underlying its behavioral expression. Here, we review research on habituation in the nematode Caenorbabditis elegans that addresses habituation at behavioral, neural circuit, and genetic levels. This work highlights the need to understand the dynamics of a behavior before attempting to determine its underlying mechanism. In many cases knowing the characteristics of a behavior can direct or guide a search for underlying cellular mechanisms. We have highlighted the importance of interstimulus interval (ISI) in both short- and long-term habituation and suggested that different cellular mechanisms might underlie habituation at different ISIs. Like other organisms, C. elegans shows both accumulation of habituation with repeated training blocks and long-term retention of spaced or distributed training, but not for massed training. Exposure to heat shock during the interblock intervals eliminates the long-term memory for habituation but not the accumulation of short-term habituation over blocks of training. Analyses using laser ablation of identified neurons, and of identified mutants have shown that there are multiple sites of plasticity for the response and that glutamate plays a role in long-term retention of habituation training.
\end{abstract}

Habituation, dishabituation, and sensitization are traditionally considered to represent nonassociative forms of learning because these forms of learning are thought to involve only a single stimulus, rather than an association between two stimuli. In their classic reviews, Thompson and Spencer (1966) and Groves and Thompson (1970) listed the behavioral characteristics of habituation and of sensitization. Habituation was defined as a decrease in responding as a result of repeated stimulation. Sensitization was defined as an increase in response magnitude as a result of a stimulus that increases arousal. In their review, Groves and Thompson (1970) considered dishabituation a special form of sensitization. Dishabituation was defined as facilitation of a decremented or habituated response. Many people assume that because these nonassociative forms of learning are the most basic and simple forms of learning they must be fully understood on a cellular level. The cellular mechanisms of both short- and long-term sensitization have been established through work with the marine mollusk Aplysia californica (for review, see Sahley and Crow 1998). In addition, work on Aplysia has distinguished between sensitization and dishabituation both behaviorally (Marcus et al. 1986) and physiologically (Hochner et al. 1988) and indicated that these are independent processes. The distinction between sensitization and dishabituation was confirmed in the leech using serotonin depletion techniques (Ehrlich et al. 1992).

Habituation is the foundation of selective attention, in that it allows animals to ignore common, irrelevant stimuli

Corresponding author.

E-MAIL crankin@cortex.psych.ubc.ca; FAX (604) 822-6903.

Article and publication are at www.learnmem.org/cgi/doi/ 10.1101/lm.37801. so that they can attend to stimuli important for survival. Habituation has been demonstrated in all organisms tested including, single celled protozoa (Wood 1970), fruit flies (Duerr and Quinn 1982), Aplysia (Pinsker et al. 1970), fish (Peeke and Peeke 1973), rats (Davis 1970), and humans (Geer 1966). The basic features of habituation first described by Thompson and Spencer (1966) and Groves and Thompson (1970) hold true across all organisms studied. This observation gives support for the hypothesis that the behavioral expression of habituation is critical for survival and has not been altered significantly through evolution. From this it would be reasonable to hypothesize that the cellular mechanisms of habituation might also be highly conserved across phylogeny. Thus far, surprisingly little is known about the mechanisms of habituation in any organism. In our laboratory we are trying to understand habituation by using behavioral, neural circuit, and genetic approaches with the model system Caenorhabditis elegans.

\section{C. elegans as a Model System}

C. elegans provides an ideal model system for examining habituation at different levels of analyses. This worm has a nervous system that is comprised of 302 neurons of which the anatomical connections have been mapped at the electron microscope (EM) level (Ward et al. 1975; Ware et al. 1975; White et al. 1986; Hall and Russell 1991). Because it is transparent, noninvasive neural circuit analyses can be done using laser ablation of identified neurons. C. elegans is a self-fertilizing hermaphrodite that can also cross-fertilize, allowing for both homozygous and heterozygous offspring. The entire worm genome has been mapped and sequenced as well (Hodgkin et al. 1998), allowing for the use of for-

LEARNING \& MEMORY 8:63-69 @ 2001 by Cold Spring Harbor Laboratory Press ISSN1072-0502/01 \$5.00

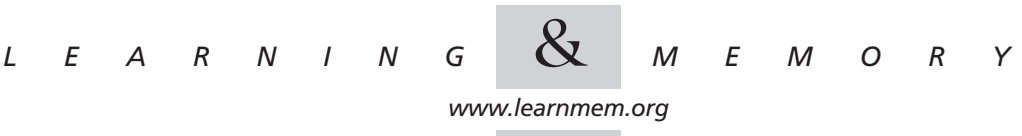


ward and reverse genetic techniques to elucidate the molecular mechanisms of habituation.

\section{Behavioral Analyses of Short-Term Habituation}

C. elegans responds to the mechanical stimulus of a tap delivered to the side of the Petri dish it inhabits by swimming backwards. This backward swimming has been called the tap withdrawal response (Rankin et al. 1990). Behaviorally, the tap withdrawal response can habituate, dishabituate, and sensitize (Rankin et al. 1990). Rankin et al. (1990) quantified habituation in C. elegans by measuring the distance traveled backwards to each tap; with repeated taps the average distance traveled progressively diminished, or habituated. Rankin and Broster (1992) found that, as in other organisms, habituation in C. elegans is sensitive to the frequency of stimulation. For example, if taps are presented at a short interstimulus interval (ISI) (i.e., 2 or $10 \mathrm{sec}$ ) the tap withdrawal response habituates at a faster rate and more completely than if the taps are presented at a longer ISI (i.e., $60 \mathrm{sec}$ ). After training, the habituated response spontaneously recovered to baseline levels. Spontaneous recovery occurred faster in worms trained at short ISIs, whereas habituation training at longer ISIs resulted in much slower recovery (Fig. 1).

This ISI-dependent difference in rate of spontaneous recovery is a very important behavioral feature of habituation as it is found in all organisms tested (Groves and Thompson 1970; Broster and Rankin 1994). It is also seen at the cellular level in the siphon withdrawal response in Aplysia in the spontaneous recovery of excitatory postsynaptic

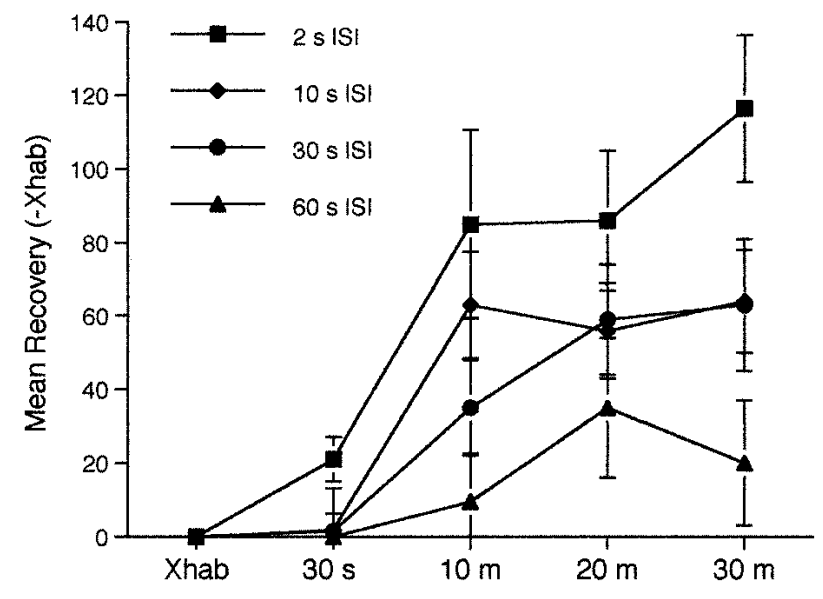

Figure 1 Spontaneous recovery is ISI dependent. Spontaneous recovery ( $n=10$ per group) for habituation following 60 stimuli delivered at 2, 10, 30, and $60 \mathrm{sec}$ ISIs measured at $30 \mathrm{sec}, 10,20$, and 30 min after habituation training. Recovery is shown as an increase in percent initial response magnitude from the habituated level (determined for each ISI by subtracting the mean of the last three responses of habituation training for that ISI from itself and from each of the recovery points). Recovery is more rapid following habituation at short ISIs $(2,10 \mathrm{sec})$ than following long ISIs (60 sec). potentials in motor neurons after the sensory-motor neurons response was decremented with different ISIs (Byrne 1982). Although many investigators, including Groves and Thompson (1970) considered dishabituation to be one of the key features distinguishing habituation from fatigue or sensory adaptation the sensitivity of spontaneous recovery to ISI of training may be a better feature. The rate of spontaneous recovery from habituation at long and short ISIs is opposite to what would be predicted for recovery from fatigue (or adaptation). Short ISIs produce greater response decrement than long ISIs; if this decrement were the result of fatigue or adaptation one would predict that the less decremented long ISI group would recover faster than the more decremented short ISI group. However, in habituation the finding is opposite this prediction: The short ISI group with greater levels of decrement recovers more rapidly than the long ISI group with less response decrement. The effect of ISI on spontaneous recovery is clearly a property of the same or related mechanisms to those involved in habituation. At the same time we know very little about the relationship between the cellular processes underlying habituation and dishabituation. It is not known whether dishabituation is simply the reversal of the process that produces habituation or whether it is a separate facilitory process superimposed on habituation that then wears off while habituation is undergoing spontaneous recovery. Thus, we propose that the ISI-dependent rate of spontaneous recovery from habituation is an excellent tool to distinguish habituation from fatigue or sensory adaptation.

One hypothesis that grows out of the studies on the effects of ISI on habituation is that habituation is not the result of a single cellular process, but rather is composed of a number of different processes; long and short ISIs may recruit subsets of overlapping and nonoverlapping cellular processes. Rankin and Broster (1992) showed that the ISI of habituation is the most important determinant of the spontaneous recovery rate in $C$. elegans once habituation reached asymptotic levels. Neither relative level of habituation, nor number of tap stimuli, played large roles in determining the rate of recovery. The data suggested that after relatively few stimuli, ISI somehow directed the rate of recovery from habituation, or rephrased, that the ISI of stimulation differentially affected the cells and that the mechanisms of habituation at different ISIs were not identical. One might suggest that different short-term memory processes were initiated by short and long ISIs, with the memory for short ISIs fading more rapidly than the memory for training at long ISIs. This hypothesis is supported by data from studies of long-term habituation in C. elegans.

\section{Behavioral Analyses of Long-Term Habituation}

C. elegans can retain memory for habituation training for $\$ 24 \mathrm{~h}$ under the proper conditions. The distributed train-

\section{$\begin{array}{lllllllllllllll}\text { www.learnmem.org } & & & & & & & & & & & \end{array}$}


ing protocol used to produce long-term memory for habituation (LTH) in the worm consisted of three blocks of 20 taps given at a $60 \mathrm{sec}$ ISI with a $1 \mathrm{~h}$ rest period between blocks. LTH was seen only when the training stimuli within the blocks were delivered at long ISIs $(60 \mathrm{sec})$ and not with distributed habituation training at short ISIs $(10 \mathrm{sec})$ or with massed training at any ISI (Beck and Rankin 1995). This differential effectiveness of long and short ISIs in producing LTH supports the previous hypothesis that short ISIs may be acting on a different molecular pathway than long ISIs.

When heat shock $\left(32^{\circ} \mathrm{C}\right.$ for $\left.40 \mathrm{~min}\right)$ was delivered during the $1 \mathrm{~h}$ rest periods in a distributed LTH training protocol, long-term retention was blocked (Fig. 2). Heat shock results in cellular stress and animals generally respond to heat shock by making heat shock proteins and ceasing all other nonessential functions including the synthesis of other proteins (Lindquist 1986). Therefore, when protein synthesis was interrupted during the $1 \mathrm{~h}$ rest periods between training blocks, worms showed no long-term retention for habituation training. Heat shock given prior to training or prior to testing had no effect on LTH retention. Beck and Rankin (1997) were able to demonstrate that heat shock administered for only $15 \mathrm{~min}$ during the first $30 \mathrm{~min}$ of the $1 \mathrm{~h}$ rest periods disrupted long-term retention. Interestingly, although the heat shock blocked any long-term memory for habituation, it did not block the accumulation of habituation across the three blocks of training. Thus, the

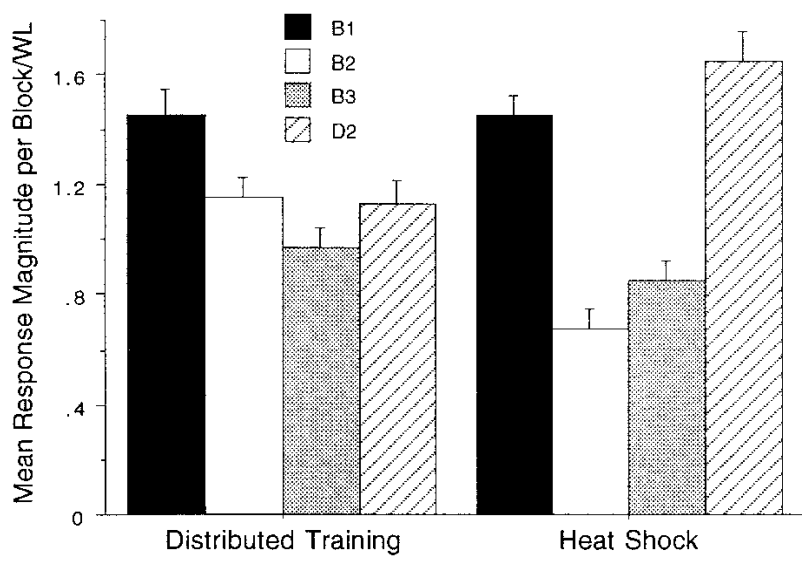

Figure 2 Distributed training produces long-term memory for habituation; that memory can be blocked by exposure to heat shock. Average response magnitude per block divided by worm length for spaced blocks of training for long-term habituation (Distributed Training) and for distributed long-term habituation training with heat shock in between blocks (Heat Shock). In each set of bars the first three (B1, B2, and B3) represent the mean response in block 1 , 2 , or 3 of distributed training on Day 1 . The fourth bar (D2) in each graph is the average response magnitude on Day 2. For Distributed Training long-term habituation is reflected in the D2 average response being significantly lower than the Block 1 average response. For the Heat Shock group, long-term memory for the Day 1 training is blocked (the D2 average response is not different from the Block 1 average response) by heat shock administered between the blocks on Day 1. accumulation of habituation across the $4 \mathrm{~h}$ training session was mediated by a different mechanism than long-term habituation.

\section{Context Conditioning in Habituation}

Although habituation is traditionally thought of as nonassociative in nature, organisms are predisposed to make associations and to learn about stimuli that predict biologically significant events. An example of this type of association is context conditioning in which an organism learns about the environmental context for an event. Worms are capable of context conditioning with habituation training (Rankin 2000). If worms were habituated in the presence of a distinctive environmental cue such as a chemical taste (contextual cue) and then were rehabituated an hour later in the presence of that cue there was greater retention of the habituation training than if they were tested without the context cue being present. The context cue had to consistently signal occurrence of the tap stimulus to enhance retention of habituation training. If the worm was exposed to the context cue for the $1 \mathrm{~h}$ period prior to training, and then received habituation training and testing in the presence of this same cue, the worm showed learned irrelevance or latent inhibition, and the context effect disappeared. Worms also showed extinction of the context association if exposed to the cue for the $1 \mathrm{~h}$ rest period between habituation training and testing. Taken together, these findings support the notion that retention of habituation can be affected by associations and that context cues can serve as facilitory associative components for retention of habituation training. These findings are consistent with studies on crabs (Chasmagnathus) showing that context influences retention of long-term habituation (Tomsic et al. 1998).

\section{Neural Circuit Analyses}

Because of its small nervous system (302 neurons) and known neuronal connections, the worm permits researchers to address the biology of habituation at the anatomical, neuronal, and molecular levels. The neural circuit that underlies habituation was determined by laser-ablating individual neurons and examining the resulting effect on the tap-withdrawal response. Chalfie et al. (1985) had previously mapped the neural circuit underlying head-touch-mediated backward movement and tail-touch-mediated forward movement. In addition to the five sensory neurons (ALMs, PLMs, and AVM) and the eight interneurons (AVAs, AVBs, AVDs, and PVCs) that Chalfie et al. (1985) identified in the touch circuits, the tap-withdrawal response circuit also includes two PVD sensory neurons and the DVA interneuron (Wicks and Rankin 1995; Fig. 3A). These additional cells likely play a role in integrating mechanosensory information as both the PVDs and the DVA synapse with anterior and posterior integration circuitry. These additional neu-

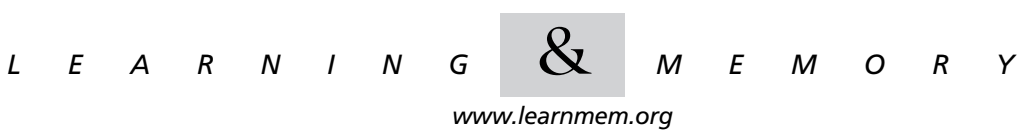


A

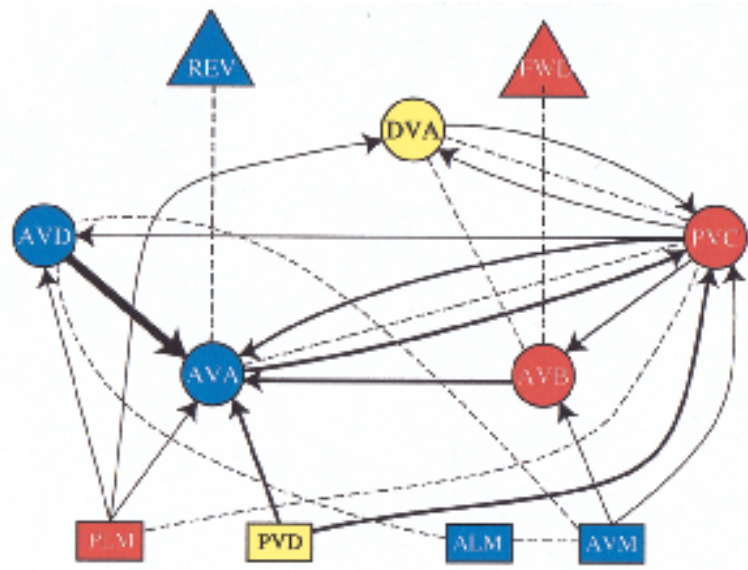

B

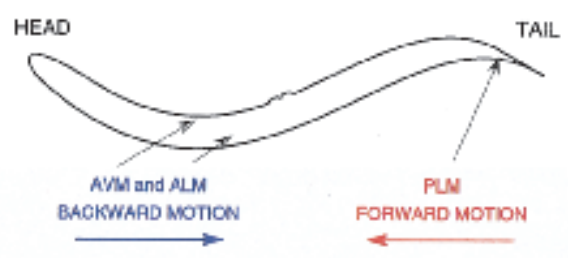

BEFORE HABITUATION

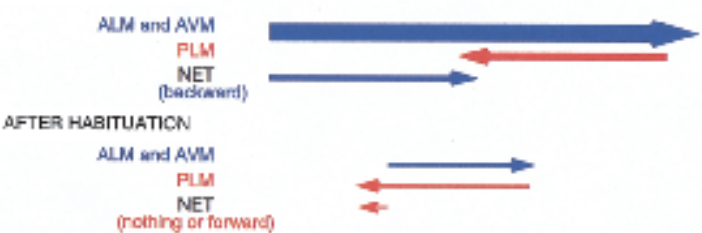

Figure 3 (A) The neural circuit for the response to tap. The hypothesized circuit that mediates the tap withdrawal response consists of seven sensory neurons (rectangles), nine interneurons (circles), and two motoneuron pools (triangles) that drive forward (FWD) or backward (REV) movement. All cells represent bilateral classes of cells except AVM and DVA, which are single cells. Chemical connections are indicated by arrows, with the number of synaptic contacts being proportional to the width of the arrow. Gap junctions are indicated by dotted lines. This circuit has been simplified for ease of presentation in two ways. First, the bilateral symmetry of the circuit has been collapsed and second, only connections with an average of $>5$ synapses are shown. The red cells represent the head-touch reversal response circuit and the blue cells depicting the tail-touch acceleration response circuit. Yellow cells represent cells hypothesized to play a role in integrating the two responses when a worm responds to tap. $(B)$ The location of the sensory neurons that transduce the tap, as well as a representation of the contribution of the two competing circuits to the response to tap, prior to habituation and following habituation. The thickness of the lines represents the strength of the response.

rons are necessary because the tap activates both the headtouch and the tail-touch circuit simultaneously and the competing responses must be integrated to produce a single behavior. Thus the decision to move forward (an acceleration) or backward (a reversal) in response to a tap stimulus is likely made in the integration circuitry represented by the interneurons of the tap-withdrawal neural circuit. In adult worms the initial response to tap is a reversal $>85 \%$ of the time (Chiba and Rankin 1990).

Because the two competing touch sensory circuits are combined in the tap-withdrawal circuit, it was important to determine whether habituation affected the circuits differently. Wicks and Rankin (1996) examined the kinetics of habituation in each of the two subcircuits by laser-ablating either the head-touch or the tail-touch neurons in the tapwithdrawal circuit prior to habituation training. Interestingly, the two competing reflexes (reversals and accelerations) habituated at different rates. The accelerations forward produced by the tail-touch circuit habituated very slowly at both 10 and 60 sec ISIs, with worms tested at a 10 sec ISI sensitizing before they habituated. The backward reversals produced by the head-touch circuit did not show this sensitization and habituated at a faster rate than the accelerations at both ISIs, but at a slower rate than those of intact worms. In the intact worm, the habituation of reversal responses is made up of the integration of the habituation kinetics of the different elements of the circuit (Fig. 4). The importance of this finding is to highlight the notion that the activity/plasticity in a single cell or cell type may not correspond directly with behavior and that it is important to understand how all of the circuit elements contribute to the behavior. In addition, these results also suggest that a single stimulus protocol (habituation training) activates different cellular processes in the head- and tail-touch neurons.

\section{Possible Site of Plasticity}

Ablation studies have also led us to hypothesize the prob-

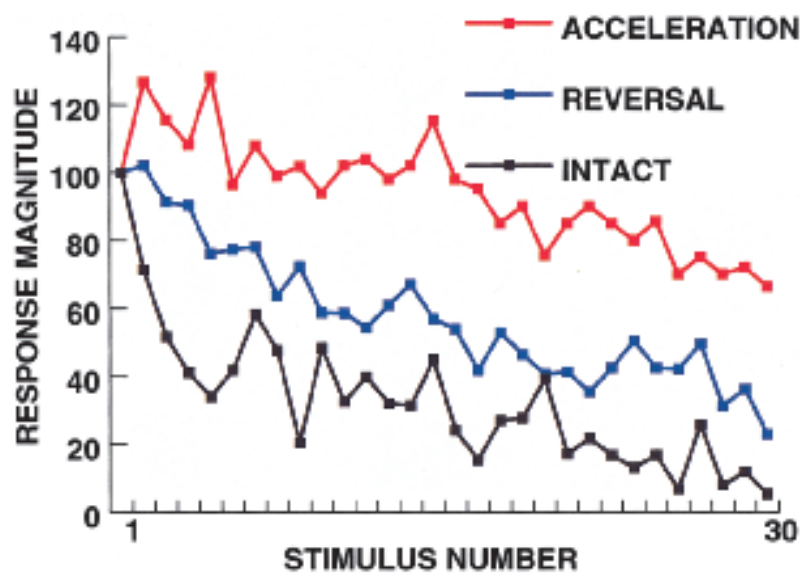

Figure 4 Line chart demonstrating the different kinetics of habituation curves to stimuli delivered at a $10 \mathrm{sec}$ ISI for "pure" accelerations compared to "pure" reversals and intact worms. Pure accelerations and reversals were produced by laser-ablating the sensory neurons of the competing touch circuits. The behavior of the intact worm can be reproduced fairly well by subtracting the accelerations from the reversals at each point on the curve. This represents the observation that the behavior of intact worms is an integration of different habituation kinetics in the two competing responses.

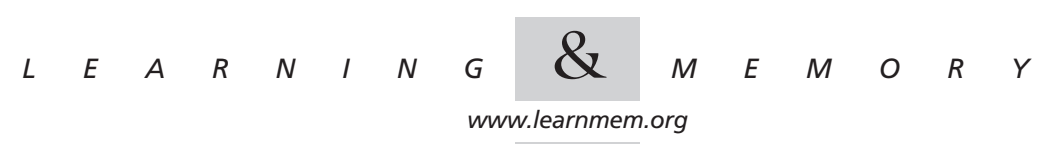


able location of synaptic changes that underlie habituation training. Wicks and Rankin (1997) were able to make inferences about the locus of plasticity by looking at the effects of habituation to tap on other behaviors that require some or all of the interneurons and motor neurons of this circuit. When they looked at the frequency and magnitude of "spontaneous reversals" (reversals with no obvious external trigger) they found no difference in either measure between tap-habituated and nonhabituated worms. They also investigated the effect of tap-withdrawal habituation on reversals in response to a thermal stimulus. Worms typically reverse (swim backwards) in response to a heat probe placed in front of them. When the responses to the heat probe were compared between tap-habituated worms and nonhabituated worms, there were no differences in the response magnitudes. If the plasticity occurred at the level of the interneurons, or the motor neurons and/or their interconnections, spontaneous reversals, and reversals to thermal stimuli that use the same interneurons should have been affected by the habituation to tap. Because other behaviors were not affected by habituation to tap the most likely sites of plasticity for habituation to tap are the sensory neurons and/or their synapses onto the interneurons.

\section{Genetic Analyses of Short- and Long-Term Habituation}

There are many thousands of identified mutants in C. elegans (for a partial list, see Riddle et al. 1997). Knowing the locus of plasticity for habituation to tap allows one to select mutations in genes that are in the cells of interest for study. Thus the tentative identification of the site of plasticity has lead to an investigation of possible genes that underlie habituation of the tap-withdrawal response. Recent evidence has led to the suggestion that the chemical synapses from the sensory neurons of the tap withdrawal circuit onto the interneurons may be glutamatergic. Several labs have isolated genes that code for glutamate receptors, that include glr-1 (homologous to AMPA type; Hart et al. 1995; Maricq et al. 1995), avr-15 (glutamate-gated Cl-channel; Dent et al. 1997) and $n m r-1$ (homologous to NMDA-type channels, Brockie et al. 1997). All three of these glutamate receptor types are expressed in one or more of the four interneurons (AVA, AVB, AVD, and PVC) that play a central role in the tap-withdrawal response. In addition, a gene for a second type of glutamate-gated chloride channel, avr-14, produces glutamate receptors that may serve as autoreceptors as it is expressed in the sensory neurons (Dent 2000).

Other evidence for glutamatergic transmission comes from investigations of eat-4, a gene isolated in a screen for feeding defects in C. elegans (Avery 1993). The eat-4 gene was described by Lee et al. (1999) who have shown that EAT-4 is specifically involved in neurons that use glutamate transmission to relax the pharynx at the end of a contraction. EAT- 4 shows strong homology to a brain-specific mam- malian (rat) sodium dependent inorganic phosphate cotransporter (BNPI) that has been identified as a vesicular glutamate transporter in hippocampal neurons (Bellocchio et al. 2000). Lee et al. (1999) showed that eat-4 was expressed in the sensory neurons, ALM, AVM, and PLM, that transduce the tap. Thus there is both pre- and postsynaptic evidence supporting the hypothesis that chemical synapses between the touch cells and the interneurons are glutamatergic.

Rankin and Wicks (2000) studied the tap-withdrawal response and habituation of this response in the eat- $4 \mathrm{mu}-$ tant. Worms with the eat- 4 mutation showed normal reversal responses to single tap stimulus indicating that the neural circuit for the tap-withdrawal response remains intact in the mutant. However, the eat- 4 worms did show changes in habituation to tap when compared to wild-type worms. eat-4 worms showed more rapid and complete habituation at 2, 10, and $60 \mathrm{sec}$ ISIs and slower spontaneous recovery from habituation than did wild-type worms. Interestingly, the effects of ISI on both habituation and on spontaneous recovery found for wild-type worms (Rankin and Broster 1992) although blunted by a floor effect, were maintained in the eat-4 mutants (Fig. 5). One of the traditional hypothesized mechanisms of habituation is transmitter depletion. However, the differential effects of long and short ISIs on habituation in the eat- 4 worms indicate that simply lowering the level of available neurotransmitter does not eliminate all of the characteristic features of habituation. The ISI effects are independent of the amount of neurotransmitter available as the response levels at each recovery timepoint are lower in the eat-4 worms, but the ISI dependent pattern is unchanged. This suggests that more active processes than transmitter depletion are involved in the mechanisms of habituation.

In addition to altered habituation, Rankin and Wicks (2000) also found that, unlike wild-type worms, the eat-4 worms did not show dishabituation of the response to tap. In these studies dishabituation was produced by a brief electric shock passed through the agar under the worm. This suggests that although the amount of available transmitter does not alter some of the characteristics of habituation, it does greatly affect dishabituation. Therefore, a conclusion from this finding might be that the mechanisms of dishabituation are distinct from some of the mechanisms of habituation, and may require the vesicular transporter eat 4 . This makes the use of dishabituation as the key feature that distinguishes habituation from fatigue or sensory adaptation problematic. The earlier observation that the ISI dependency of spontaneous recovery can also distinguish habituation from fatigue or sensory adaptation now assumes new importance. The eat- 4 worms showed pronounced habituation, yet did not show dishabituation. If dishabituation were the defining feature of habituation, this would lead one to conclude that the decreased responding to tap found

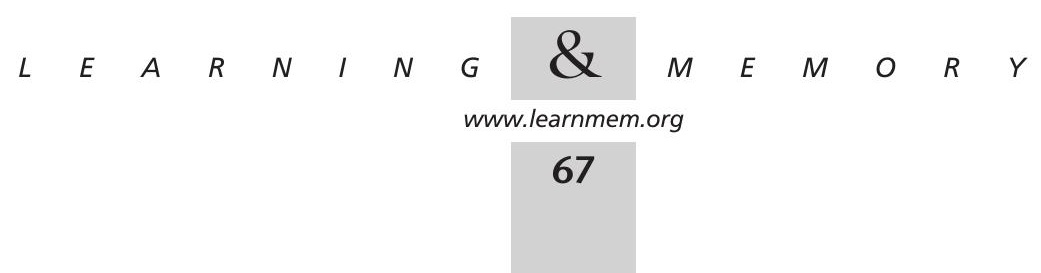




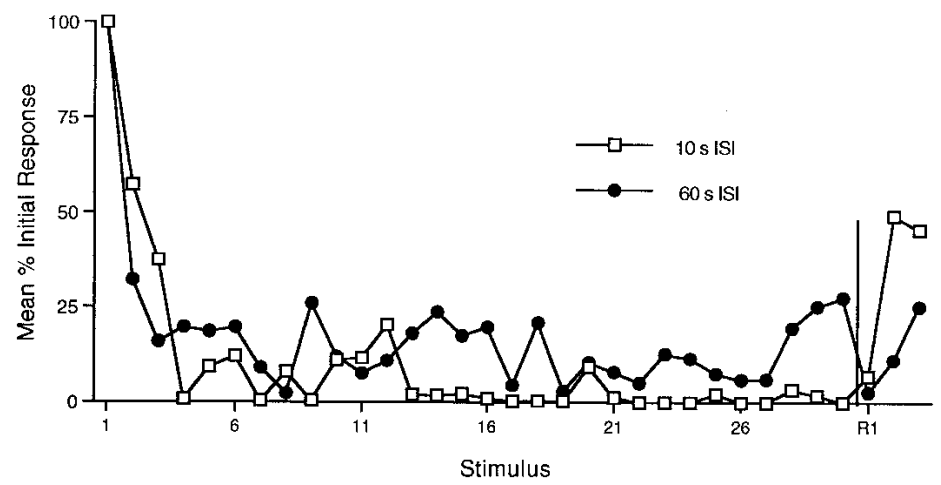

Figure 5 Reversal responses of eat- 4 worms shown as the mean percent initial response across 30 tap stimuli with three recovery taps at $30 \mathrm{sec}, 5$, and $10 \mathrm{~min}$ after habituation training. eat-4 mutants show rapid habituation at both 10 and $60 \mathrm{sec}$ ISI. The 10 sec ISI curve reflects more complete habituation and more rapid spontaneous recovery than the $60 \mathrm{sec}$ ISI curve.

with eat-4 mutants was not habituation. The effects of ISI on habituation and spontaneous recovery in eat-4 worms suggest that this conclusion would be an error. Therefore, it is important to include the role of ISI in habituation and in spontaneous recovery as a defining feature of habituation.

Finally, in recent studies of long-term memory in $C$. elegans we have shown that although eat-4 worms show profound short-term habituation, they do not show $24 \mathrm{~h}$ retention of LTH with taps (Rose and Rankin, unpubl.). This further supports the notion that the neurotransmitter glutamate may be critical for the formation of long-term memories for the tap withdrawal response. We are currently studying the role of mutations in a number of the identified glutamate receptor genes to determine their role in longterm memory.

\section{Summary}

From the first published report of habituation in C. elegans in 1990 (Rankin et al.) the behavioral parameters for shortterm and long-term habituation (Rankin and Broster 1992; Beck and Rankin 1995, 1997; Rankin 2000) have been described, the neural circuit for the tap withdrawal response has been determined (Wicks and Rankin 1995, 1996, 1997) and now, genes involved in both long-term and short-term habituation are being studied (Rankin and Wicks 2000). $C$. elegans has proven to be a useful model system for untangling the secrets of the mechanisms of habituation. Because they are small, inexpensive, and easy to maintain in the laboratory we have been able to do large parametric analyses of behavior that would not be possible in mammals. Because of their small nervous systems it has been possible to directly determine the cells involved in the behavior and determine putative sites of plasticity. And finally, because of the vast body of knowledge available on C. elegans genetics, an analysis of genes that play a role in habituation of the tap withdrawal response has been greatly facilitated.

C. elegans shows types of learning and memory that demonstrate adherence to the same behavioral rules as in vertebrate systems. The initial genetic analysis shows that the neurotransmitter glutamate, which is a major player in studies of learning and memory in vertebrate systems, also is important to learning and memory in C. elegans. This adds credibility to generalizing the mechanisms found to underlie learning and memory in C. elegans to other species. From our work thus far it is clear that habituation is not mediated by a single cellular process, but by a large number of processes, some of which are recruited by long ISIs, some by short ISIs, and some by all ISIs. By continuing these analyses of habituation in C. elegans it is our hope that over the next decade this model system will help us to understand habituation, the foundation of all other learning processes.

\section{REFERENCES}

Avery, A. 1993. The genetics of feeding in Caenorhabditis elegans. Genetics 133: 897-917.

Beck, C.D.O. and Rankin, C.H. 1995. Long-term habituation is produced by distributed training at long ISIs and not by massed training or short ISIs in Caenorhabditis elegans. Anim. Learn. Behav. 25: 446-457. . 1997. Heat shock disrupts long-term memory consolidation in Caenorhabditis elegans. Learn. \& Mem. 2: 161-177.

Bellocchio, E.E., Reimer, R.J., Fremeau, R.T., and Edwards, R.H. 2000. Uptake of glutamate into synaptic vesicles by an inorganic phosphate transporter. Science 289: 957-960.

Brockie, P.J., Madsen, D.M., and Maricq, A.V. 1997. Genetic analysis of two C. elegans putative NMDA receptor subunits $n m r-1$ and $n m r-2$. Soc. Neurosci. Abstr. 23: 936.

Broster, B.S. and Rankin, C.H. 1994. Effects of changing interstimulus interval during habituation in Caenorhabditis elegans. Behav. Neurosci. 108: 1019-1029.

Byrne, J.H. 1982. Analysis of synaptic depression contributing to habituation of gill-withdrawal reflex in Aplysia californica. $J$ Neurophysiol. 48: 431-438.

Chalfie, M., Sulston, J.E., White, J.G., Southgate, E., Thomson, J.N., and Brenner, S. 1985. The neural circuit for touch sensitivity in Caenorhabditis elegans. J. Neurosci. 5: 956-964.

Chiba, C.M. and Rankin, C.H. 1990. A developmental analysis of spontaneous and reflexive reversals in the nematode C. elegans. $J$. Neurobiol. 21: 543-554.

Davis, M. 1970. Effects of interstimulus interval length and variability on

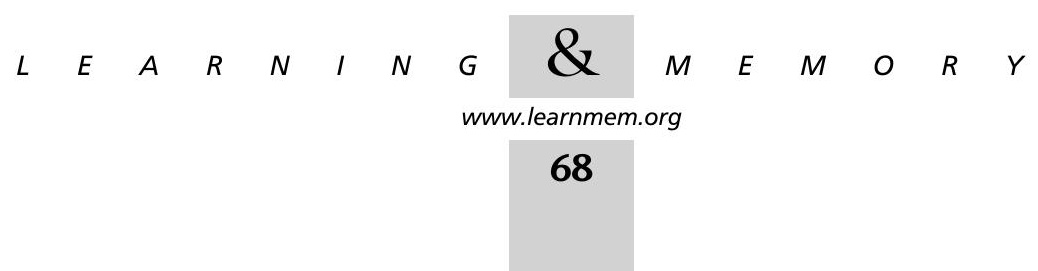


startle response habituation in the rat. J. Comp. Physiol. Psychol. 72: $177-192$

Dent, J.A., Davis, M.W., and Avery, L. 1997. avr-15 encodes a chloride channel subunit that mediates inhibitory glutamatergic neurotransmission and ivermectin sensitivity in Caenorhabditis elegans. ЕМВO J. 16: 5867-5879.

Dent, J.A., Smith, M.M., Vassilatis, D.K., and Avery, L. 2000. The genetics of ivermectin resistance in Caenorhabditis elegans. Proc. Natl. Acad. Sci. 97: 2674-2679.

Duerr, J.S. and Quinn, W.G. 1982. Three Drosopbila mutations that block associative learning also affect habituation and sensitization. Proc. Natl. Acad. Sci. 79: 3646-3650.

Ehrlich, J.S., Boulis, N.M., Karrer, T., and Sahley, C.L. 1992. Differential effects of serotonin depletion on sensitization and dishabituation in the leech, Hirudo medicinalis. J. Neurobiol. 23: 270-279.

Geer, J.H. 1966. Effect of interstimulus intervals and rest-period length upon habituation of the orienting response. J. Exp. Psychol. 72: 617-619.

Groves, P.M. and Thompson, R.F. 1970. Habituation: A dual-process theory. Psychol. Rev. 77: 419-450.

Hall, D.H. and Russell, R.L. 1991. The posterior nervous system of the nematode Caenorhabditis elegans: Serial reconstruction of identified neurons and complete pattern of synaptic interactions. J. Neurosci. 11: $1-22$.

Hart, A.C., Sims, S., and Kaplan, J.M. 1995. Synaptic code for sensory modalities revealed by $C$. elegans GLR-1 glutamate receptor. Nature 378: 82-85.

Hochner, B., Klein, M., Schacher, S., Kandel, E.R. 1986. Additional component in the cellular mechanism of presynaptic facilitation contributes to behavioral dishabituation in Aplysia. Pros. Natl. Acad. Sci. 83: 8794-8798.

Hodgkin, J., Horvitz, J.R., Jasny, B.R., and Kimble, J. 1998. C. elegans: Sequence to Biology. Science 282: 2011.

Lindquist, S. 1986. The heat-shock response. Annu. Rev. Biochem. 55: 1151-1191.

Lee, R.Y.N., Sawin, E.R., Chalfie, M., Horvitz, H.R., and Avery, L. 1999. EAT-4, a homolog of a mammalian sodium-dependent inorganic phosphate co-transporter, is necessary for glutamatergic neurotransmission in Caenorhabditis elegans. J. Neurosci. 19: 159-167.

Marcus, E.A., Nolen, T.G., Rankin, C.H., and Carew, T.C. 1988. Behavioral dissociation of dishabituation, sensitization, and inhibition in Aplysia: Evidence for a multi-process view of non-associative learning. Science 241: 210-213.

Maricq, A.V., Peekol, E., Driscoll, M., and Bargmann, C. I. 1995. Mechanosensory signaling in C. elegans mediated by the GLR-1 glutamate receptor. Nature 378: 78-81.

Peeke, H.V.S. and Peeke, S.C. 1973. Habituation in fish with special reference to intraspecific aggressive behavior. In Habituation 1 (ed. H.V.S. Peeke and M.J. Herz), pp. 59-83. Academic Press, San Diego, CA.
Pinsker, H., Kupfermann, I., Castellucci, V., and Kandel, E.R. 1970 Habituation and dishabituation in the gill withdrawal reflex in Aplysia. Science 926: 1740-1742.

Rankin, C.H. 2000. Context conditioning in habituation in the nematode Caenorhabditis elegans. Behav. Neurosci. 114: 496-505.

Rankin, C.H. and Broster, B.S. 1992. Factors affecting habituation and recovery from habituation in the nematode Caenorhabditis elegans. Behav. Neurosci. 106: 239-242.

Rankin, C.H. and Wicks, S.R. 2000. Mutations of the Caenorbabditis elegans brain-specific inorganic phosphate transporter eat-4 affect habituation of the tap-withdrawal response without affecting the response itself. J. Neurosci. 20: 4337-4344.

Rankin, C.H., Beck, C.D.O., and Chiba, C.M. 1990. Caenorhabditis elegans: A new model system for the study of learning and memory. Behav. Brain Res. 37: 89-92.

Riddle, D.L., Blumenthal, T., Meyer, B.J., and Priess, J.R. 1997. Appendix 1. In C. elegans II (ed. ), pp. 902-1047. Cold Spring Harbor Laboratory Press, Cold Spring Harbor, NY.

Sahley, C. and Crow, T. 1998. Invertebrate learning: Current perspectives In Neurobiology of Learning and Memory (eds. J. Martinez and R. Kesner), pp. 177-209. Academic Press, San Diego, CA.

Thompson, R.F. and Spencer, W.A. 1966. Habituation: A model phenomenon for the study of neuronal substrates of behavior. Psychol. Rev. 73: 16-43.

Tomsic, D., Pedriera, M.E., Romano, A., Hermitte, G., and Maldonado, H. 1998. Context-US association as a determinant of long-term habituation in the crab Chasmagnathus. Anim. Learn. Behav. 26: 196-209.

Ward, S., Thomson, N., White, J.G., and Brenner, S. 1975. Electron microscopical reconstruction of the anterior sensory anatomy of the nematode Caenorhabditis elegans. J. Comp. Neurol. 160: 313-337.

Ware, R.W., Clark, D., Crossland, K., and Russel, R.L. 1975. The nerve ring of the nematode Caenorbabditis elegans: Sensory input and motor output. J. Comp. Neurol. 162: 71-110.

White, J.E., Southgate, E., Thomson, J.N., and Brenner, S. 1986. The structure of the nervous system of the nematode Caenorbabditis elegans. Philos. Trans. R. Soc. Lond. B. Sci. 314: 1-340.

Wicks, S.R. and Rankin, C.H. 1995. Integration of mechanosensory stimuli in Caenorhabditis elegans. J. Neurosci. 15: 2434-2444.

1996. The integration of antagonistic reflexes revealed by laser ablation of identified neurons determines habituation kinetics of the Caenorhabditis elegans tap withdrawal response. J. Comp. Physiol. [A] Sensory Neural Behav. Physiol. 179: 675-685.

- 1997. The effects of tap withdrawal response habituation on other withdrawal behaviors: The localization of habituation in C. elegans. Behav. Neurosci. 111: 342-353.

Wood, D.C. 1970. Parametric studies of the response decrement produced by mechanical stimuli in the protozoan, Stentor coeruleus. $J$. Neurobiol. 1: 345-360. 


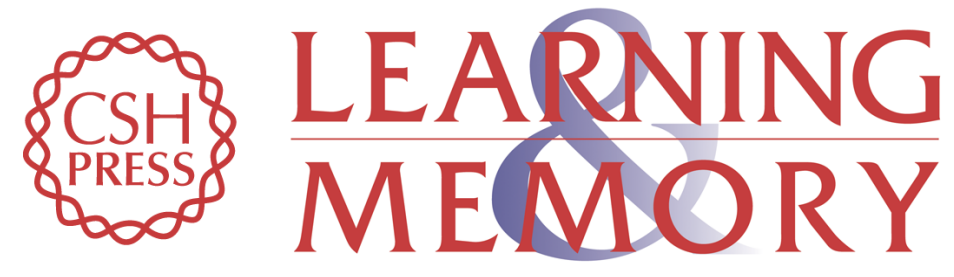

\section{Analyses of Habituation in Caenorhabditis elegans}

Jacqueline K. Rose and Catharine H. Rankin

Learn. Mem. 2001, 8:

Access the most recent version at doi:10.1101//m.37801

References This article cites 35 articles, 12 of which can be accessed free at: http://learnmem.cshlp.org/content/8/2/63.full.html\#ref-list-1

License

Email Alerting Receive free email alerts when new articles cite this article - sign up in the box at the Service top right corner of the article or click here. 